Published in final edited form as:

$J$ Am Chem Soc. 2006 January 18; 128(2): 418-419.

\title{
Selective Labeling of Extracellular Proteins Containing Polyhistidine Sequences by a Fluorescein-Nitrilotriacetic Acid Conjugate
}

\author{
Christian R. Goldsmith $\dagger$, Jacek Jaworski $\ddagger$, Morgan Sheng $\ddagger$,§, and Stephen J. Lippard $\dagger$ \\ † Department of Chemistry, Massachusetts Institute of Technology, Cambridge, Massachusetts \\ 02139 \\ $\ddagger$ Picower Center for Learning and Memory and Howard Hughes Medical Institute, Massachusetts \\ Institute of Technology, Cambridge, Massachusetts 02139 \\ $\S$ RIKEN-MIT Neuroscience Research Center, Massachusetts Institute of Technology, Cambridge, \\ Massachusetts 02139
}

Fluorescent tags have facilitated the study of protein localization and dynamics involving living cells. ${ }^{1}$ The most commonly used labels are fluorescent proteins (FPs). Although of indisputable value, the application of FPs introduces several problems. The size of the FP can prevent a critical component of the labeled construct from achieving its natural structure, function, or locale. Wild-type versions of common FPs have a tendency to oligomerize. ${ }^{1}$ Last, the $\mathrm{pH}$ sensitivity of FPs limits their ability to image acidic regions of the cell. Genetic modification can sometimes overcome these limitations, but this process is labor-intensive. ${ }^{2}$

Using fluorescent small molecules as the label can mitigate such difficulties. Synthetic probes are generally less demanding sterically than proteins and can be attached to the target peptide with minimal disruption of native structure and function. Photophysical and acid-base properties can be altered more easily and tailored to suit an application of interest. The set of methodologies used to attach the probes to biological targets is limited. ${ }^{3}$ Previous fluorescent small-molecule probes have relied on the interaction of $\mathrm{O}^{6}$-benzylguanine with $\mathrm{O}^{6}$ -

alkylguanine-DNA alkyltransferase, ${ }^{4}$ the enzyme-mediated incorporation of biotin analogues, 5 or the affinity of nitrilotriacetic acid (NTA) complexes of nickel(II) for polyhistidine sequences 6,7 to append synthetic fluorophores to proteins with minimal genetic perturbation. Of the manipulations required for these methods, the last is perhaps the most innocuous.

$\mathrm{His}_{6}$ tags are often incorporated into the termini of peptides in order to facilitate purification, usually with minimal impact on protein folding. ${ }^{8}$ The attachment does have the drawback of being $\mathrm{pH}$-sensitive. Previous use of paramagnetic $\mathrm{Ni}^{2+}$ to bridge modified NTAs and $\mathrm{His}_{6}$ components quenched much of the fluorophore emission $(\Phi<0.10)$, limiting their application in biological systems. ${ }^{6,9}$ Here, we report a significant advance over this earlier work through the isolation and photophysical characterization of a probe (NTA-DCF, where DCF is 2', 7'dichlorofluorescein) lacking this shortcoming. The resulting construct is quite unusual in that it remains highly luminous $(\Phi=0.72)$ upon binding $\mathrm{Ni}^{2+} .6,10-12$ This property allows NTADCF to serve as a small yet highly fluorescent label for polyhistidine sequences. The probe is notable for its facile synthesis, the brightness of its emission, its small size relative to the

E-mail: lippard@mit.edu

Supporting Information Available: Synthetic details; emission spectra of NTA-DCF and $\mathrm{Ni}^{2+}{ }_{-\mathrm{NTA}} \mathrm{DCF}$; cell permeability study; color versions of Figures 1 and 2 showing expanded control studies; mass spectrum of $\mathrm{Ni}^{2+}-\mathrm{NTA}-\mathrm{DCF}$ adduct; cell toxicity study. This material is available free of charge via the Internet at http://pubs.acs.org. 
commonly used FPs, and its ability to label polyhistidine sequences selectively through its NTA targeting moiety. These properties enable its use in microscopy.

The compound NTA-DCF can be synthesized in one step through established chemistry 13 from the 6-carboxy-2',7'-dichlorofluorescein-3',6'-diacetate succinimidyl ester ${ }^{14}$ and the commercially available $N, N$-bis(carboxymethyl)-L-lysine hydrate (Scheme 1 ). The product precipitates from acidified solutions in high purity, without the need for chromatography.

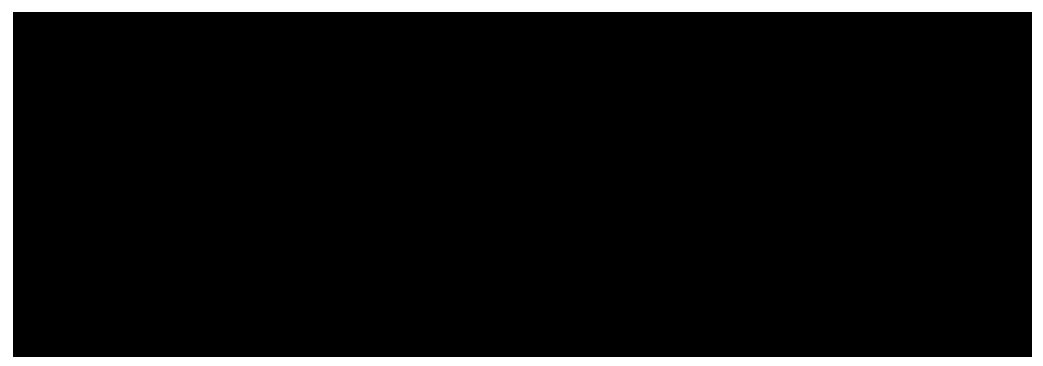

\section{Scheme 1.}

The photophysical properties of the fluorophore are not significantly impacted by the NTA functionality installed at the 6-position of the fluorescein ring. The absorption band for NTADCF at $504 \mathrm{~nm}\left(\varepsilon=86000 \mathrm{M}^{-1} \mathrm{~cm}^{-1}\right)$ is similar to the $504 \mathrm{~nm}\left(\varepsilon=75000 \mathrm{M}^{-1} \mathrm{~cm}^{-1}\right)$ band for DCF. ${ }^{15}$ Similarly, the emission of NTA-DCF $\left(\lambda_{\max }=527 \mathrm{~nm}, \Phi=0.78\right)$ resembles that of DCF $\left(\lambda_{\max }=526 \mathrm{~nm}, \Phi=0.88\right) .{ }^{16}$ Upon addition of $\mathrm{NiCl}_{2}$ to a solution of NTA-DCF in a buffer of $50 \mathrm{mM}$ piperazine $N, N^{\prime}$-bis(2-ethanesulfonic acid (PIPES), $100 \mathrm{mM} \mathrm{KCl}$, and $\mathrm{KOH}$ to $\mathrm{pH} 7.0$, the fluorescence decreases only minimally (5\%, Figure S1), contrasting sharply with the $75 \%$ loss observed in a Cy5-NTA conjugate. ${ }^{9}$ Low-resolution mass spectrometry confirms the complexation of $\mathrm{Ni}^{2+}$ to NTA-DCF, and the solution $\mu_{\text {eff }}$ value of $2.7(3) \mu_{\mathrm{B}}(292 \mathrm{~K}, \mathrm{MeOH}-$ $d_{4}$ ) is consistent with a $\mathrm{d}^{8}$ metal ion coordinated in an octahedral geometry, as anticipated from the known crystal structures of $\mathrm{Ni}^{2+}-\mathrm{NTA}$ complexes. ${ }^{17}$ During the preparation of this manuscript, a closely related NTA-fluorescein conjugate lacking the chlorine atoms on the $2^{\prime}$ and $7^{\prime}$ positions, mono-NTA, was described. ${ }^{7}$ The photophysical properties of the isolated dye and the impact of $\mathrm{Ni}^{2+}$ on its emission were not reported, however.

The NTA-DCF dye does not enter cells either by itself or as its $\mathrm{Ni}^{2+}$ adduct (Figure $\mathrm{S} 2$ ). This impermeability was exploited to label and image selectively proteins on the extracellular side of the cell membrane. When premixed with an equimolar concentration of $\mathrm{NiCl}_{2}, \mathrm{NTA}-\mathrm{DCF}$ fluorescently labels polyhistidine sequences expressed on the outer surfaces of HeLa and HEK 293-T cells transfected with pDisplay plasmid containing a 6xHis encoding sequence (Figures 1 and 2). The binding of the probe is blocked when $\mathrm{Ni}^{2+}$ is unavailable (Figure 1) or the polyhistidine tag is not expressed (Figure 2), indicating that both of these components are required for fluorescent labeling. Consistent with these results, the addition of a $5 \mathrm{mM}$ concentration of the extracellular metal chelator EDTA to the cellular medium prevents NTADCF from binding to the cells. In the absence of EDTA or a similar metal scavenging agent, the labeled protein construct persists for at least $20 \mathrm{~min}$ after washing (Figure S3). It is likely that its stability, which has not yet been fully assessed, is comparable to those of other His $6^{-}$ $\mathrm{Ni}^{2+}-\mathrm{NTA}$ conjugates, for which the $\mathrm{His}_{6}-$ probe $K_{\mathrm{d}}$ value is in the $1-20 \mu \mathrm{M}$ range. ${ }^{6,7}$ For the closely related mono-NTA compound, the $K_{\mathrm{d}}$ value is $14 \pm 4 \mu \mathrm{M}^{7}$ A nuclear morphology study suggests that the dye is not toxic at the $5 \mu \mathrm{M}$ dose administered to the cell cultures (Figure S6). 18

In summary, we present the synthesis and characterization of a fluorescent nickel-NTAfluorescein probe and demonstrate its ability to mark extracellular proteins containing genetically programmable polyhistidine sequences. The emission of the free dye is not 
significantly impacted by complexation of the paramagnetic $\mathrm{Ni}^{2+}$ ion, a novelty in fluorescence spectroscopy. The $\mathrm{Ni}^{2+}-\mathrm{NTA}-\mathrm{DCF}$ conjugate should prove valuable in applications to study the functions of cell surface proteins and, after appropriate synthetic modification, intracellular components as well. Although the attachment is weaker since it does not feature a kinetically irreversible bond between the probe and a particular amino acid residue as in some methods, $4,19,20$ the labeling may be more selective for an intended target since it is directed at a peptide sequence rather than a single residue.

\section{Acknowledgment}

This work was supported by grant GM 65519 from the National Institute of General Medical Sciences (S.J.L.). C.R.G. is an NIH postdoctoral fellow and M.S. an Investigator for the Howard Hughes Medical Institute. We thank Dr. K. R. Barnes for assistance with cell studies and Prof. A. Y. Ting for helpful comments.

\section{References}

1. Zhang J, Campbell RE, Ting AY, Tsien RY. Nat. Rev. Mol. Cell Biol 2002;3:906-918. [PubMed: 12461557]

2. Stepanenko OV, Verkhusha VV, Kazakov VI, Shavlovsky MM, Kuznetsova IM, Uversky VN, Turoverov KK. Biochemistry 2004;43:14913-14923. [PubMed: 15554698]

3. Chen I, Ting AY. Curr. Opin. Biotechnol 2005;16:35-40. [PubMed: 15722013]

4. Keppler A, Pick H, Arrivoli C, Vogel H, Johnsson K. Proc. Natl. Acad. Sci. U.S.A 2004;101:99559959. [PubMed: 15226507]

5. Chen I, Howarth M, Lin W, Ting AY. Nature Methods 2005;2:99-104. [PubMed: 15782206]

6. Guignet EG, Hovius R, Vogel H. Nat. Biotechnol 2004;22:440-444. [PubMed: 15034592]

7. Lata S, Reichel A, Brock R, Tampé R, Piehler J. J. Am. Chem. Soc 2005;127:10205-10215. [PubMed: 16028931]

8. Woestenenk EA, Hammarströ M, van der Berg S, Härd T, Berglund H. J. Struct. Funct. Genet 2004;5:217-229.

9. Kapanidis AN, Ebright YW, Ebright RH. J. Am. Chem. Soc 2001;123:12123-12125. [PubMed: 11724636]

10. Burdette SC, Walkup GK, Spingler B, Tsien RY, Lippard SJ. J. Am. Chem. Soc 2001;123:78317841. [PubMed: 11493056]

11. Jiang L-J, Luo Q-H, Wang Z-L, Liu D-J, Zhang Z, Hu H-W. Polyhedron 2001;20:2807-2812.

12. Torrado A, Walkup GK, Imperiali B. J. Am. Chem. Soc 1998;120:609-610.

13. Liu C, Hudson RHE, Petersen NO. Synthesis 2002;10:1398-1406.

14. Woodroofe CC, Masalha R, Barnes KR, Frederickson CJ, Lippard SJ. Chem. Biol 2004;11:1659_ 1666. [PubMed: 15610850]

15. Leonhardt H, Gordon L, Livingston R. J. Phys. Chem 1971;75:245-249.

16. Mchedlov-Petrossyan NO, Kleshchevnikova VN. J. Chem. Soc., Faraday Trans 1994;90:629-640.

17. Salam A, Aoki K. Inorg. Chim. Acta 2000;311:15-24.

18. Foglieni C, Meoni C, Davalli AM. Histochem. Cell Biol 2001;115:223-229. [PubMed: 11326750]

19. Yin J, Liu F, Li X, Walsh CT. J. Am. Chem. Soc 2004;126:7754-7755. [PubMed: 15212504]

20. George N, Pick H, Vogel H, Johnsson N, Johnsson K. J. Am. Chem. Soc 2004;126:8896-8897. [PubMed: 15264811] 
A)

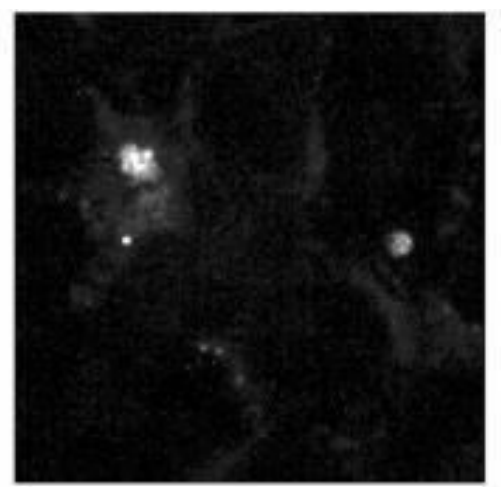

C)

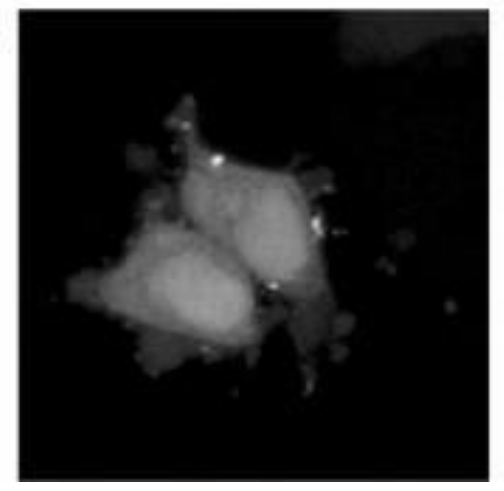

B)

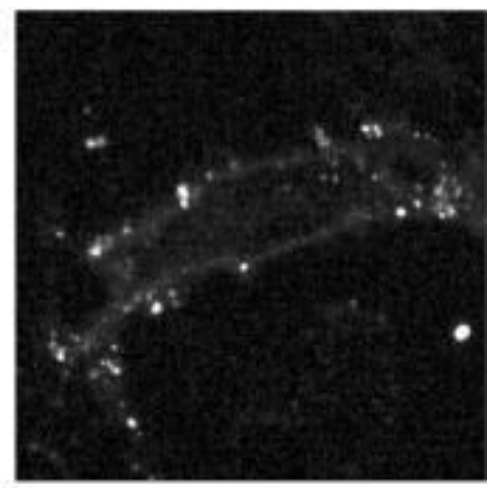

D)

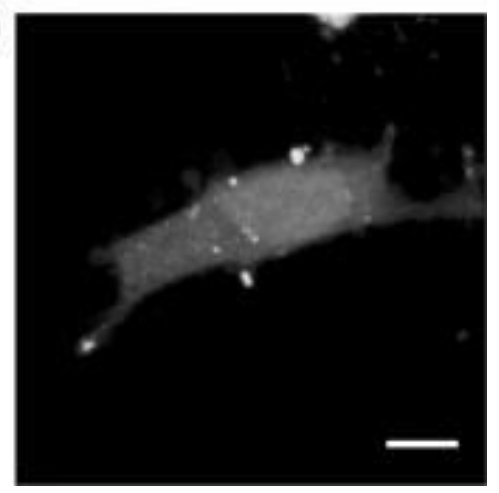

Figure 1.

HeLa cells separately transfected with Red Fluorescent Protein (mRFP) and extracellular His $_{6}$-tagged protein. Cells were treated with $5 \mu \mathrm{M}$ NTA-DCF and either (A) $0 \mu \mathrm{M}$ or (B) 5 $\mu \mathrm{M} \mathrm{NiCl}_{2}$ for $5 \mathrm{~min}$, washed once with phosphate-buffered saline (PBS) prior to fixation, and imaged. Images $\mathrm{C}$ and $\mathrm{D}$ show the mRFP emission corresponding to the cells imaged in $\mathrm{A}$ and $\mathrm{B}$, respectively. The scale bar in D represents $10 \mu \mathrm{m}$. Note that, whereas most of the transfected cells express both introduced proteins, some will express one but not the other since double transfection is not fully efficient. Figure S3 portrays a two-color version of this figure. 

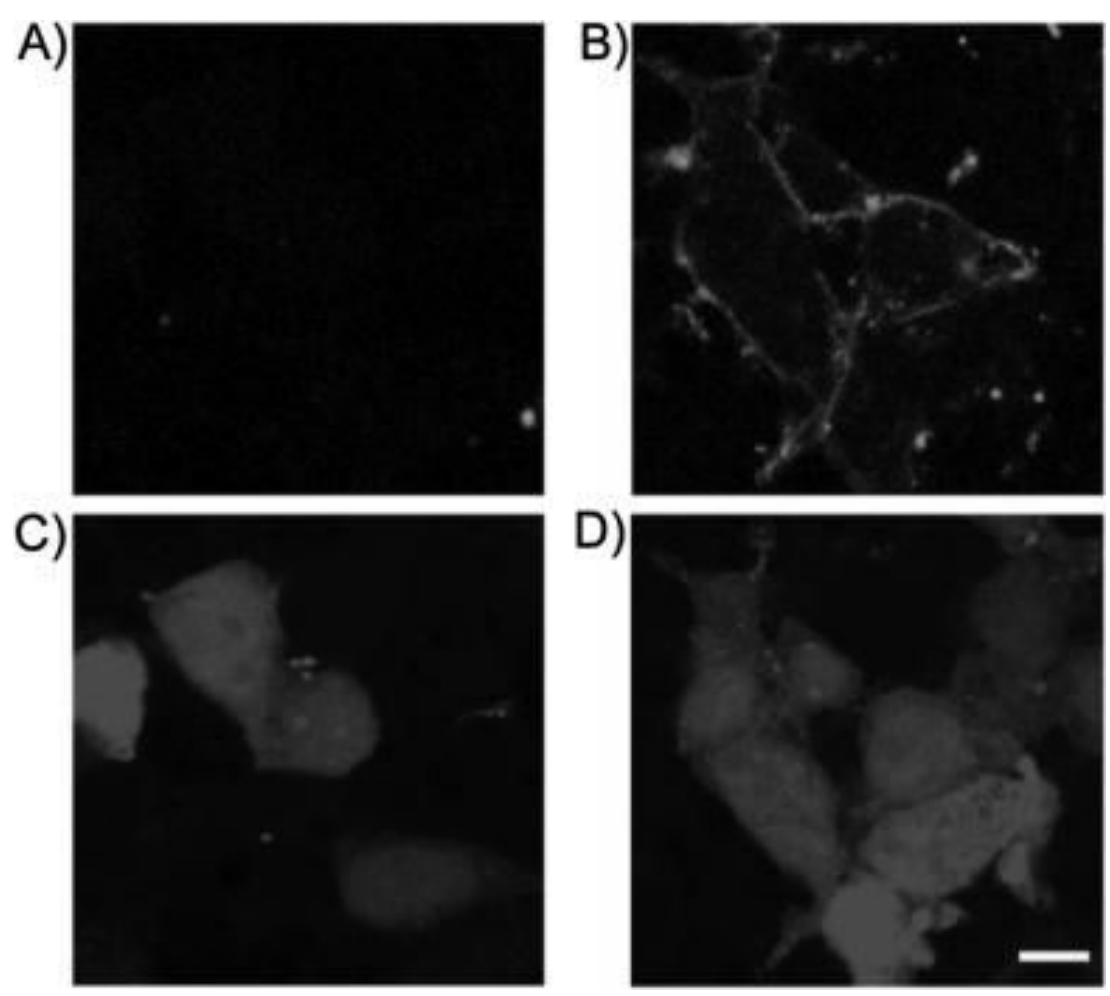

Figure 2.

HEK 293-T cells separately transfected with Red Fluorescent Protein (mRFP) and either (A) pDisplay or (B) pDisplay-6xHis, which installs His 6 sequences on the extracellular side of the cell membrane. Images A and B display the emission from added NTA-DCF dye, whereas C and D show the fluorescence from mRFP from the cells in A and B, respectively. Both cell samples were treated with $5 \mu \mathrm{M}$ NTA-DCF and $5 \mu \mathrm{M} \mathrm{NiCl}_{2}$ for $5 \mathrm{~min}$, washed once with phosphate-buffered saline (PBS), fixed, and imaged. The scale bar in D represents $10 \mu \mathrm{m}$. Cells do not express mRFP and pDisplay-6xHis uniformly (see caption, Figure 1). Figure S4 portrays a two-color version of this figure. 